\title{
La maestranza de las Atarazanas Reales de Barcelona durante el siglo XVI
}

\author{
A. Jorge Aguilera López \\ Museu Marítim de Barcelona
}

\section{Resumen}

En el enfrentamiento cristiano-musulmán en el Mediterráneo durante el siglo Xvi, en el que la Monarquía Hispánica jugó un papel protagonista, el elemento clave fueron las galeras. Estos buques se reinventaron para adaptarse a las nuevas formas de hacer la guerra y fue por ello que poblaron como nunca antes las aguas del Mediterráneo. Este tema de estudio ha sido siempre muy popular entre los investigadores, quienes se han acercado a él y lo han enfocado desde los más diversos puntos de vista. A pesar de ello — con la excepción del caso veneciano-, se sabe relativamente poco acerca de los artesanos que se encargaban de construir las galeras, y el vacío informativo es más notable cuando ponemos nuestra atención en Barcelona. Las Atarazanas Reales de Barcelona, la principal fábrica de galeras de la Monarquía, han sido mal interpretadas y poco estudiadas para los siglos modernos, y esa es la situación que la investigación que aquí perseguimos pretende revertir.

Palabras clave: atarazanas, Barcelona, galeras, Felipe II, construcción naval, guerra marítima, Lepanto.

* Este artículo se ha realizado gracias a la financiación de la Fundació de Suport al Museu Marítim i Drassanes Reials de Barcelona, en cuyo proyecto de investigación se enmarca este trabajo. 
La mestrança de les Drassanes Reials de Barcelona al segle XVI

\section{Resum}

En l'enfrontament cristià-musulmà al Mediterrani durant el segle xvi en el qual la Monarquia Hispànica va tenir un paper protagonista, les galeres van ser l'element clau. Aquests bucs es van reinventar per adaptar-se a les noves formes de fer la guerra i per això van poblar com mai abans les aigües del Mediterrani. Aquest tema d'estudi ha estat sempre molt popular entre els investigadors, els quals s'hi han acostat i l'han enfocat des dels punts de vista més diversos. Malgrat això —i exceptuant el cas venecià-, se sap relativament poc dels artesans que s'encarregaven de construir les galeres, i el buit informatiu és especialment greu quan posem l'atenció a Barcelona. Les Drassanes Reials de Barcelona — la principal fabrica de galeres de la Monarquia- han estat tradicionalment mal interpretades i poc estudiades pel que fa als segles moderns i aquesta és la situació que la recerca que persegueixo pretén revertir.

Paraules clau: drassanes, Barcelona, galeres, Felip II, construcció naval, guerra marítima, Lepant.

\section{The shipbuilders of the Royal Shipyard of Barcelona during the 16th century}

\section{Abstract}

In the Christian-Muslim confrontation in the Mediterranean during the I6th century, in which the Hispanic Monarchy played a leading role, galleys were the key element. These ships were reinvented and adapted to the new forms of warfare, and they populated the waters of the Mediterranean like never before. This subject of study has always been very popular among researchers, who have approached and considered it from many diverse points of view. Despite this - and except for the Venetian case-relatively little is known about the artisans who were responsible for building the galleys, and the information gap is especially serious when we turn our attention to Barcelona. The Royal Shipyard of Barcelona, the main builder of galleys of the Monarchy, has traditionally been misinterpreted and little studied over the early modern period, and this is the situation that the research I pursue here aims to reverse.

Keywords: shipyards, Barcelona, galleys, Felipe II, naval construction, maritime war, Lepanto. 


\section{El Mediterráneo: un mar de galeras}

Las galeras y sus bases logísticas fueron, desde el punto de vista militar, el elemento clave en las confrontaciones bélicas del teatro de operaciones mediterráneo durante los primeros siglos modernos y, por tanto, también fue en ellas donde se concretó el mayor esfuerzo inversor, tecnológico y armamentístico del período por parte de la Monarquía Hispánica. ${ }^{I}$ No cabe duda de que la construcción naval era parte destacada de la más sofisticada vanguardia tecnológica disponible en el dinámico mundo renacentista. En aquella circunstancia histórica, el tipo de barco bélico de remos mediterráneo, que a finales del siglo xv había llegado a ser considerado por algunos como obsoleto, ${ }^{2}$ estaba destinado a renacer y experimentar un desarrollo espectacular a lo largo de los siglos XVI y XVII.

Durante el conflictivo siglo xv, las armadas peninsulares se conformaron con el recurso de utilizar embarcaciones mixtas, tanto de guerra a cargo de la Corona como de mercantes de particulares —estas últimas embargadas y adaptadas, mediante obras de fortificación que las hicieran más operativas para actuar junto a las escuadras de galeras, que seguían siendo los buques de guerra básicos en aquellos tiempos-. No obstante, la expansión económica que se había de iniciar tan dinámicamente en las postrimerías de este siglo fue posible gracias al desarrollo en las costas atlánticas hispanas de barcos mancos de alto bordo, en especial naos y carabelas - veleros fuertes, rápidos y mucho más autónomos que las fustas-, cuya eficacia los acabaría haciendo presentes en todos los mares del

I. Irving A. A. Thompson, «Las galeras en la política militar española en el Mediterráneo durante el siglo XvI», Manuscrits: Revista d'Història Moderna, 24 (2006), pp. 95-I24.

2. En estos términos escribía a los Reyes Católicos su cronista y armador Diego de Valera alrededor de I480: «Y al parecer mío, y de otros que más saben que yo, V. A. no debe de galeras empacharse, porque son muy costosas y poco provechosas para los mares de acá, é de invierno no pueden servir», en Diego DE VALERA, Epistolas de mosén Diego de Valera embiadas en diversos tiempos é á diversas personas, José Antonio de Balenchana, ed. y trad., Sociedad de Bibliófilos Españoles, Madrid, I878, p. 78. 
planeta. Estos buques, junto con algunas de las grandes carracas mediterráneas, entraron en competencia con las galeras; su mayor capacidad de carga no solo les disputó los tráficos mercantiles marítimos entre el gran meridional y el del norte, sino que también era la responsable de que los buques fueran más eficaces en las acciones bélicas, gracias, entre otras cosas, a la mayor cantidad y calibre de la pesada artillería de hierro forjado que, de forma progresiva, fueron incorporando a sus costados y castillos. ${ }^{3}$

En la España de los Reyes Católicos, a la conclusión de la guerra de Granada, solo quedaba una escuadra de cuatro galeras para la defensa de aquella costa y para evitar el contacto de los moriscos que permanecían en la península con los musulmanes de Berbería, además de otra escuadra de seis unidades mantenida en el virreinato de Sicilia, ambas formaciones gestionadas mediante «asiento» con particulares. Los magníficos edificios de las Atarazanas Reales de galeras de las riberas atlánticas, es decir, los de Santander y los de Sevilla, o bien fueron abandonados o sus funciones quedaron reducidas a la mínima expresión; las atarazanas de Santander se dejaron arruinar y las de Sevilla acabaron siendo convertidas en base logística y arsenal de apresto de las flotas de Indias; ${ }^{4}$ las pocas galeras guardacostas de Granada se apoyaron en los puertos de Cádiz, Gibraltar, Málaga y Cartagena. Venecia fue la única potencia cristiana que mantuvo operativo a todos los efectos su contingente de galeras en el Mediterráneo, tanto para la guerra como para el comercio y el lucrativo transporte de peregrinos a Tierra Santa. La profunda crisis de la marina catalana condenó a la casi paralización a las fábricas en las atarazanas de Barcelona.

3. José Luis CASAdo Soto, «Los barcos del Atlántico ibérico en el siglo de los descubrimientos. Aproximación a la definición de su perfil tipológico», en B. Torres Ramírez, coord., Andaluciá, América y el mar, Diputación de Huelva, Sevilla, I99I, pp. I2I-I43.

4. José Luis Casado Soto «Reconstrucción de las Reales Atarazanas de Galeras de Santander», Anuario del Instituto de Estudios Maritimos Juan de la Cosa, 5 (1983-1986), pp. 57-84; Pablo Emilio Pérez-Mallaína Bueno, «Las Reales Atarazanas de Sevilla, I252-I493. Un astillero medieval en el extremo occidental de Europa», en D. González Cruz, coord., Descubridores de América: Colón, los marinos y los puertos, Sílex, Madrid, 2012, pp. 349-367. 
La realidad es que fue mínima la proporción de galeras respecto a la masa de barcos de alto bordo que partieron en las grandes armadas espańolas aprestadas para las expediciones a Italia: en la de I495, setenta y cinco naves, cuatro galeras y veintiún leños menores; en la de I500, fueron setenta las naves, tres carracas y solo siete galeras. Para la conquista de Orán, en I509, se utilizaron ochenta naos y diez galeras. ${ }^{5}$ Estos hechos no implican que, en situaciones especialmente críticas, no se siguieran prefiriendo las galeras. Tal ocurrió con motivo del viaje a Italia del rey Fernando, en I505, empresa que se realizó en una formación de dieciséis naves cantábricas, tres carracas genovesas y dieciséis galeras, nueve de las cuales se construyeron ex profeso para la ocasión en las atarazanas de Barcelona —arsenal que experimentó por momentos la recuperación de la febril actividad que había caracterizado su brillante pasado- ${ }^{6}$ Algo parecido tuvo lugar en I52I, para la armada aprestada también en Barcelona, destinada al traslado a Italia del obispo de Tortosa Adriano de Utrecht — quien sería elegido papa-, compuesta en esta ocasión por dieciséis galeras y treinta naos. ${ }^{7}$

Una vez reprimida la revuelta de los moriscos iniciada en el Albaicín en I500, su expulsión, decretada dos años más tarde, tuvo el efecto rebote de incrementar las acciones corsarias desde las bases del norte de África. Ello motivó la continuación de la política de establecimiento de presidios y puertos fortificados a lo largo de las costas del Magreb. Normalizada la ocupación de Melilla, Cazaza y Mazalquivir, se procedió a la conquista de Orán, prolongada con la toma de Bujía y Trípoli y el sometimiento a vasallaje de Argel y Túnez, empresas estas últimas protagonizadas por el militar e ingeniero Pedro Navarro en $1510 .{ }^{8}$ Asimismo, las guerras provo-

5. Dichas referencias las encontramos en el primer tomo de la todavía utilísima obra de Cesáreo Fernández Duro, Historia de la Armada Española desde la unión de los reinos de Castilla y León, 9 vols., Sucesores de Rivadeneyra, Madrid, I895, vol. I, pp. 15,34 y 73 .

6. El inventario de estas nueve galeras está localizado en Archivo de la Corona de Aragón (ACA), Real Patrimonio (RP), Serie General 2339, f. I.

7. Fernández Duro, Historia de la Armada, vol. I, p. I35.

8. Uno de los factores esenciales que movió la expansión peninsular al otro lado del estrecho de Gibraltar era intentar acabar con los daños que provocaban los piratas en las costas de Andalucía y Levante, que impedían que el poblamiento y el desarrollo 
cadas por la invasión francesa de Italia en I494, que concluirían con la hegemonía española sobre la península itálica a mediados del siglo XVI. Todas estas actuaciones, dirigidas a garantizar las comunicaciones entre las dos grandes penínsulas del Mediterráneo occidental, así como la seguridad de las costas frente a los corsarios, definieron el ámbito espacial incluido entre el estrecho de Gibraltar y el de Mesina. ${ }^{9}$ Las novedosas técnicas arquitectónicas de fortificación hispanas respondieron con eficiencia y sofisticada solidez a los avances imparables de la artillería puesta en juego, a la que se fueron incorporando progresivamente las piezas de bronce. ${ }^{\text {Io }} \mathrm{La}$ zona marítima del Mediterráneo occidental así definida fue denominada por Piri Reis —el más destacado de los geógrafos y cartógrafos turcos contemporáneos, ubicado en el núcleo del poder que acechaba desde el otro extremo del gran mar interior — como «el mar espańol» (Ispanyol Bahriye). ${ }^{\text {II }}$

económico de la costa se produjeran de una manera adecuada. Sobre el tema escriben: José Enrique López de Coca Castañer, El reino de Granada en la época de los Reyes Católicos: repoblación, comercio y frontera, Universidad de Granada, Granada, I989; y Beatriz Alonso Acero, Cisneros y la conquista española del norte de África: cruzada, política y arte de la guerra, Ministerio de Defensa, Madrid, 2005. Debemos advertir que estas empresas no fueron realizadas de manera oficial por la Corona, puesto que, aunque contaban con todo el apoyo logístico de la misma, fueron promovidas y financiadas por particulares, como es el caso de la ocupación de la plaza de Melilla. Sobre el caso de Navarro y sus acciones véase Juan Priego López, Pedro Navarro y sus empresas africanas, Consejo Superior de Investigaciones Científicas, Madrid, 1953.

9. Andrew C. Hess, The Forgotten Frontier: A History of the Sixteenth-Century Ibero-African Frontier, University of Chicago Press, Chicago / Londres, 1978. El barón de Vallelonga, en un extenso memorial, probablemente de 1560, dirigido a Felipe II, dice: «Sicilia es verdadera frontera marítima de todo Levante», en Archivo General de Simancas (AGS), Estado (EST), leg. 446, sin foliar (s. f.).

Io. Aurelio Valdés Sánchez, coord., Artillería y fortificaciones en la Corona de Castilla durante el reinado de Isabel la Católica. I474-I504, Ministerio de Defensa, Madrid, 2004; Juan Francisco Pardo Molero, La defensa del imperio. Carlos V, Valencia y el Mediterráneo, Sociedad Estatal para la Conmemoración de los Centenarios de Felipe II y Carlos V, Madrid, 200I.

II. Contamos con una bella y reciente edición en turco del Libro de las Materias Marinas: Piri Reıs, Kitab-î̀ Bahriye, Bülent Özükan, ed., Boyut Yayîn Grubu, Estambul, 2013. 
La consolidación de la voluntad expansiva de los dos grandes poderes situados en los extremos de su cuenca, así como el inevitable choque que había de producirse entre ambos, se dirimió en gran medida mediante el uso de aquellos peculiares y sofisticados barcos llamados galeras.

\section{La galera: tradición e innovación}

El siglo XVI fue, por tanto, testigo del resurgimiento de las escuadras de galeras como formidable instrumento militar de los estados en el Mediterráneo, pues mientras los océanos se abrían a las navegaciones con buques de alto bordo, propulsados en exclusiva a vela, las sutiles y frágiles galeras, movidas por una masa de remeros, no solo lograron recuperar el protagonismo de antańo, sino que se convirtieron en el elemento primordial de la fuerza de choque con que se midieron cristianos y musulmanes durante largas décadas.

La galera era barco de perfil alargado, de bajo bordo, fondo plano, poco calado y movido fundamentalmente por remos. ${ }^{12} \mathrm{La}$ utilización como fuerza motriz de los músculos humanos tiene su razón en los vientos flojos y cambiantes del ámbito marino en que navegaban las galeras, y en su característica de nave guerrera necesitada de rápida movilidad, independiente de la dirección del aire, cuando la táctica del abordaje y la de embestidas eran las más utilizadas en la guerra naval. En el siglo xvi las galeras disponían de una proa acabada en punta, o «espolón», para lanzarse contra el enemigo. Sobre la proa se levantaba un castillo, o "arrumbada", donde se situaban los cañones de mayor calibre. En la popa, plana, estaba el castillo denominado "espalda", donde se alojaba el mando. En el siglo xvi los remos eran largos, «de manilla", y movidos cada uno por cuatro o cinco remeros, normalmente esclavos y condenados — que estaban atados con cadenas y que se

I2. Francisco-Felipe Olesa Muñido, La organización naval de los estados mediterráneos y en especial de España durante los siglos XVI y XVII, 2 vols., Editorial Naval, Madrid, I968, vol. I, pp. I62-176. 
hundían con el barco en caso de naufragio-,${ }^{13}$ aunque también existían los «buenas boyas», gente contratada para remar a cambio de un salario. ${ }^{14}$ Aunque había naves con distintos órdenes de remos, prevaleció el remo grande, impulsado por varios hombres, frente a los individuales, más reducidos en tamaño, frecuentes en los navíos antiguos y medievales. ${ }^{\text {IS }}$

La galera típica enarbolaba un palo mayor y a lo sumo otro mástil en proa, el trinquete, que sostenían velas latinas o triangulares, sujetas por vergas diagonales, o «entenas». Tal disposición se había demostrado más adecuada para los vientos mediterráneos al emplearlos como ayuda a la fuerza de los remos. Sobre el palo mayor, y sobre el trinquete en ocasiones, había gavias para los vigías. Entre veinte y treinta bancos de remeros por banda daban movimiento a la nave. Aunque su fin era bélico y no tenían demasiado calado, muchas galeras servían para llevar mercaderías, y esta combinación del uso comercial y el militar desde el siglo XIII, que era frecuente, venía favorecida por la construcción de grandes galeras. ${ }^{16}$ Dentro del tipo general descrito para la familia náutica de las galeras pueden ser incluidas múltiples variantes. Las «galeazas», en algún caso denominadas "galeones» —no deben confundirse con el galeón atlántico-, eran galeras de gran tamaño, con cañones en las bandas, sobre los remeros, además de los situados en los castillos. Su

I3. Debemos mencionar aquí la excelente tesis doctoral inédita de José Manuel Marchena Giménez, «La vida y los hombres de las galeras de España (siglos XVIXVII)», Universidad Complutense de Madrid, Madrid, 2oro, donde presta especial atención a la chusma y al resto de la tripulación de galeras.

I4. Luca Lo Basso, Uomini da remo. Galee e galeotti nel Meditteraneo in età moderna, Selene, Milán, 2003.

I5. Para una visión histórica y general de la evolución de las galeras y los demás navíos rémicos, véase Roger C. Anderson, Oared fighting ships. From classical times to the coming of steam, Percival Marshall, Londres, 1962.

I6. En las órdenes que con el cargo de capitán general del Mediterráneo, se le entregaron a García de Toledo, Felipe II decía: «porque los sueldos de los oficiales principales que gobiernan la galera son bajos y para que sirvan con más voluntad y cuidado, es necesario hacerles alguna gratificación, os damos comisión para que les podáis permitir que lleven alguna cosa moderada", en AGS, Galeras (GAL), leg. I, s. f. 
arboladura contaba con tres palos: mayor, trinquete y mesana. De dimensiones más exiguas que la galera típica, la «galeota» carecía de arrumbada y contaba con menos de veinte bancos, cada uno con un solo remero. Las «fustas» eran similares a las galeazas, pero con bancos de hasta tres remeros. $\mathrm{Y}$ «bergantines», "fragatas», «falúas» y "grips» eran las denominaciones de embarcaciones de solo cinco o diez bancos, sin arrumbadas ni cubiertas. ${ }^{17}$

Como vemos, la buena adaptación del buque a los requerimientos de la "guerra moderna», ${ }^{18}$ en que las armas de fuego se manifestaron cada vez más eficaces, consiguió aprovechar las indudables cualidades tácticas de las galeras, haciéndolas más eficientes —en este ámbito mediterráneo- que los prestigiados barcos atlánticos y, por tanto, imprescindibles en el teatro de operaciones del otrora llamado Mare Nostrum.

Diferentes autores han tratado de explicar, desde perspectivas diversas, el papel desempeñado por las galeras que empleó la Monarquía Hispánica durante este período. En un principio, primó el interés por conocer la formación de armadas y la descripción de las acciones bélicas en que intervinieron, ${ }^{19}$ más tarde atrajo la atención el punto de vista táctico y estratégico, ${ }^{20}$ al que siguió el de la gestión, la administración y la financiación, ${ }^{21}$ para concluir con los aspectos armamentísti-

17. Francisco Fernández Izquierdo, «Astilleros y construcción naval de la España anterior a la Ilustración», en España y el ultramar hispánico hasta la Ilustración: I Jornadas de Historia Marítima, IHCN, Madrid, I989, pp. 39 y 40.

I8. Geoffrey PARKer, La revolución militar. Innovación militar y apogeo de Occidente, I500-I800, Alianza, Madrid, 2002 [ed. or. en inglés, I988].

19. Fernández Duro, Historia de la Armada, 9 vols., I895-1903; Ignacio Bauer Y LANDAUER, La marina española en el siglo XVI: don Francisco de Benavides, cuatralvo de las galeras de España, Imprenta de Jesús López, Madrid, I92I.

20. Las obras: Olesa Muñido, La organización naval de los estados; y FranciscoFelipe Olesa Muñido, La galera en la navegación y el combate, 2 vols., Junta Ejecutiva del IV Centenario de la Batalla de Lepanto, Madrid, I97I.

2I. Irving A. A. Thompson, Guerra y decadencia. Gobierno y administración en la España de los Austrias, Crítica, Barcelona, I98I. 
$\cos ^{22}$ y logísticos. ${ }^{23}$ Quizá está aún pendiente de un profundo estudio el aspecto tecnológico y su aparato productivo, es decir, el trabajo específico que se hacía en las atarazanas, junto con los detalles de la construcción, la progresión y, aunque más complicado, la cualificación técnica de los barcos salidos de sus picaderos, el ritmo en que se introdujeron cambios y mejoras y la cadencia y cuantificación de las labras llevadas a cabo a lo largo de estas décadas.

Al inicio del reinado de Felipe II se consideraba una galera ordinaria a la dotada, por cada banda, de veinticuatro bancos con tres remeros y otros tantos remos en cada uno. A las que tenían más de este número se las denominaba «bastardas». Veinte o treinta ańos más tarde, las galeras ordinarias tenían veintiséis bancos y no era raro que cada uno llevara cuatro remeros accionando un solo remo, de bastante mayor talla, denominado «de galocha». Tal crecimiento del tamaño y cambio del sistema de propulsión fue consecuencia de varios factores, entre los que destaca el de la entidad de la artillería incorporada a estos buques. Los cañones fueron el elemento que en mayor medida condicionó la evolución del diseńo de las galeras durante el siglo XVI, por la incorporación de la mucho más eficiente artillería de bronce, cada vez de mayor calibre y en mayor cantidad. Desde luego, no fue el único factor condicionante, puesto que también contó la necesidad de transportar un número más elevado de soldados y la cuestión del prestigio, concretado en que las reales y las capitanas fueran de hasta treinta remos o más por banda. ${ }^{24}$

La necesidad de afrontar en ocasiones las olas atlánticas también incidió en el diseńo y fortaleza de las destinadas a tal fin. El aumento

22. John Francis Guilmartin, Gunpowder and galleys: Changing technology and Mediterranean warfare at the sea in the Sixteenth Century, Cambridge University Press, Nueva York / Londres, I975 [ed. revisada, Naval Institute Press, Annapolis, 2003].

23. David Goodman, Poder y penuria. Gobierno, tecnología y ciencia en la España de Felipe II, Alianza, Madrid, I990.

24. José Luis Casado Soto, «Aproximación a la galera española en el Mediterráneo durante la época de Felipe II", en E. Belenguer Cebrià, coord., Felipe II y el Mediterráneo: La monarquía y los reinos II, 4 vols., Sociedad Estatal para la Conmemoración de los Centenarios de Felipe II y Carlos V, Madrid, I999, vol. IV, pp. 34I-344. 
de tres a cinco cañones que, en la segunda mitad de siglo, llevaban las galeras a proa, bajo la arrumbada, así como el aumento de su calibre y del de las piezas menores repartidas por los costados, convirtió estos barcos en plataformas artilleras que requirieron reforzar los escantillones de sus maderas y el número y grosor de las ligazones, para evitar que se abrieran con los golpes del retroceso producido por el disparo de las propias piezas. Y, por supuesto, también hubo que fortalecerlas para que soportaran el castigo del cañoneo enemigo. Probablemente uno de los factores que más influyó en la limitación del número de unidades a finales de siglo, además de su cada vez más elevado coste de construcción y mantenimiento, fuera la escasez y alto precio de los cañones. ${ }^{25}$

Como es obvio, existían diferencias entre las galeras construidas, por ejemplo, en las atarazanas de Barcelona o en el arsenal de Venecia, este último mucho mejor conocido y del que se suelen sacar conclusiones generales. ${ }^{26}$ Los cambios, no hay duda, fueron graduales, no uniformes y diversos, aunque globalmente convergentes. Había diferentes tradiciones constructivas que, aunque es posible que en este período se influyeran entre sí más que nunca, dado el fluido trasvase de efectivos que ocasionaron los constantes encuentros bélicos, tenían peculiaridades difíciles de suprimir, desde los diferentes sistemas metrológicos empleados en las diversas riberas donde se construían, hasta los secretos de oficio guardados con celo por los maestros carpinteros en el seno de sus familias gremiales.

25. Véase el breve pero sólido y brillante libro de Carlo Cipolla, uno de los estudiosos que más se afanaron en resaltar la importancia de poseer más artillería que el enemigo: Carlo Cipolla, Cañones y velas en la primera fase de expansión de Europa, I400-I700, Ariel, Barcelona, 1967.

26. Por citar tan solo algunos estudios sobre el tema: Ugo TuccI, «Architettura navale veneziana. Misuri di vascelli nella seconda metà del Cinquecento", Bollettino dell'Atlante Linguistico Mediterraneo, 5-6 (1963-1964), pp. 277-293; Frederic C. LANE, Navires et constructeurs à Venise pendant la Renaissance, SEVPEN, París, I965; y su posterior Venetian Ships and Shipbuilders of the Renaissance, John Hopkins University Press, Baltimore, I973; Ennio Concina, L'Arsenale della Repubblica di Venezia. Tecniche e istituzioni dal Medioevo all'età Moderna, Mondadori Electa, Milán, I984; Guido Ercole, Duri i banchi! La navi della Serenissima 42I-I797, Gruppo Modellistico Trentino, Trento, 2006. 
La guerra es siempre una confrontación condicionada, no solo por la economía y el buen hacer militar, sino también por la tecnología. La batalla en el Mediterráneo durante el siglo xvi, y sobre todo a lo largo del reinado de Felipe II, supuso asimismo, sin lugar a dudas, una dura competencia tecnológica: la pugna entre diferentes tecnologías en constate evolución y de las que, lamentablemente, conocemos muy poco. Los estudios referentes a la tecnología naval de las diferentes naciones - turca, veneciana, genovesa, catalana, castellana y demás- están todavía pendientes de factura. ${ }^{27}$

Las galeras empleadas por los Habsburgo en su lucha contra el Islam fueron labradas en las riberas mediterráneas de Espańa e Italia. En Italia, junto con la aliada Génova, fue sobre todo en Nápoles y Mesina donde se labraron los buques del rey, mientras que en España, aunque había actividad en diferentes puntos — como Málaga, Cartagena, Valencia y Tortosa-, fue en Barcelona, en concreto en las Atarazanas Reales, donde prácticamente se concentró toda la actividad fabril, ya que no solo se labraron las galeras destinadas al Mediterráneo, sino también las que operaban en el resto de la península ibérica, en especial en el estrecho de Gibraltar, así como las que se hicieron para bregar en el Atlántico y el Caribe. ${ }^{28}$ Del mismo modo, era en estas atarazanas donde se fabricaban, en exclusiva, las galeras reales. ${ }^{29}$

Es por todo ello que podemos considerar que las Atarazanas Reales de Barcelona no solo fueron el principal centro constructivo de la Monarquía Hispánica, sino también de todo el Mediterráneo occidental. A pesar de esta situación, el edificio que hoy día alberga el Museo Marítimo de Barcelona y, sobre todo, la actividad allí desarrollada durante esta época dorada y de mayor actividad nos resultan, en gran parte, desconocidos. De hecho, no ha sido hasta tiempos recientes, y gracias

27. Casado Soto, «Aproximación a la galera española», pp. 344 y 345.

28. Bibiano Torres Ramírez, "La defensa naval de las Indias durante el siglo XVI», en F. de P. Solano Pérez-Lila y F. del Pino Díaz, coords., América y la España del siglo XVI, Consejo Superior de Investigaciones Científicas, Madrid, I983, pp. II5-I25.

29. La más conocida fue la botada en $\mathrm{I} 568$, que emplearía don Juan de Austria en Lepanto y cuya hipotética réplica se exhibe hoy en el Museo Marítimo de Barcelona. 
a la arqueología, cuando se ha podido confirmar algo que parte de la historiografía ya sospechaba, y es que el edificio que ha llegado a nuestros días, a pesar de tener su origen en los siglos bajomedievales, es mayormente producto de las diferentes remodelaciones y reformas que se llevaron a cabo a partir del siglo xvi. El nuevo edificio se expandió con naves más anchas y altas, y permitió construir mayores barcos, acordes con la evolución de la navegación. ${ }^{30}$

\section{Las Atarazanas Reales de Barcelona y su maestranza}

Sin lugar a dudas, todo ello fue posible gracias a que los hombres encargados de la gestión y construcción de las embarcaciones supieron adaptar la galera a los nuevos requerimientos, convirtiéndola en el buque capaz de incorporar las tecnologías bélicas emergentes, aunque para ello fuera preciso transformar su estructura, forma, tamańo y fortaleza, a la vez que el número de unidades puestas en juego por las fuerzas en conflicto crecía sin cesar.

Las Atarazanas Reales de Barcelona —que, en origen, habían sido concebidas como una infraestructura en exclusiva al servicio del monarca一, debido a las necesidades de la Corona siglos atrás, albergaban también al Consell de Cent y a la Diputació del General. Durante el

30. Durante la segunda mitad del siglo Xvi se habría procedido al derribo de las naves medievales del lado de la montaña y se habría hecho retroceder el conjunto edificado con el fin de protegerlo de los embates del mar que amenazaban la fachada, como consecuencia del cambio de corrientes provocado por la construcción del muelle del puerto. La edificación se habría empezado por el lado de montaña y habría avanzado hacia la fachada de mar para no colapsar el funcionamiento de las instalaciones. Este proceso habría culminado con la desaparición del patio de separación entre las naves de montańa y las de mar, al integrar las segundas en la nueva edificación. Esteve Nadal i Roma y Adriana Vilardell Fernández, «Drassanes Reials», Anuari d'Arqueologia i Patrimoni de Barcelona 20II, Ajuntament de Barcelona e Institut de Cultura, Barcelona, 20II, pp. 59-63; Sílvia Dahl Termens, Enric Garcia Domingo y Olga López Miguel, Les Drassanes Reials de Barcelona, Efadós y Museu Marítim de Barcelona, Barcelona, 2013. 
período que estudiamos, a pesar de que seguían contando con talleres de su propiedad — las llamadas botigues — , el peso de ambas instituciones en la fábrica era puramente anecdótico comparado con el rol que habían tenido en los siglos XIV y XV. A pesar de ello, aportaron fondos para colaborar tanto en la reforma del edificio como en la construcción de su baluarte y elementos defensivos.

El tema del dinero fue siempre un elemento de tensión y discusión entre los consellers y la Corona. Como ejemplo que ilustra este tipo de episodios, contamos con los hechos de I552: el 30 de julio los consellers de Barcelona enviaron una carta al príncipe Felipe en la que, desesperados, pedían ayuda ante la probable llegada de un inminente ataque de las flotas turca y francesa:

Ha de arribar dita armada turquesca [...] ab la armada francesa que seran més de doscentes veles se diria que vindria en aquesta ciutat de Sa Magestat y de Sa Altessa [...]. Vist maiorment que tal gran poder no basten nostres forces defendres de tants grans enemics [...]. Com a príncep y senyor nostre perque entesa la tan gran necessitat te la dita ciutat vulla recordarse de provehir tot lo que convingue per la defensa y guarda. ${ }^{3 \mathrm{I}}$

La decisión del príncipe fue acelerar las obras defensivas de la ciudad y sobre todo proteger las atarazanas con la construcción de un nuevo baluarte a cargo del ingeniero italiano Juan Bautista Calvi. ${ }^{32}$ Es aquí cuando nos encontramos que, a pesar de pedir ayuda para la defensa ante un inminente y poderoso ataque franco-otomano, los consellers intentan ahorrarse parte del coste proponiendo recortar la altura de la muralla, cosa que escandaliza tanto al ingeniero como al contador de cuentas, Juan Muñoz de Salazar, que escribe al príncipe Felipe desde Barcelona el 5 de agosto de I552:

3I. AGS, Guerra y Marina (GyM), leg. 47, Los consellers de Barcelona al príncipe, Barcelona, 30 de julio de 1552.

32. Damià Martínez Latorre, «La fortificación de Barcelona a mediados del siglo Xvi: el baluarte de las Atarazanas y la Puerta de Mar de Giovan Battista Calvi», Drassana: Revista del Museu Maritim, I2 (2004), pp. 82-92. 
Se acabó de tomar resolución determinada que lo del baluarte que se ha de hacer a la parte de la atarazana en presencia de todos los consejeros y de Juan Bautista, ingeniero de S. M., y porque el baluarte que se ha de hacer ha de costar según lo que está asentado siete mil escudos: los cinco mil que la ciudad paga y dos mil que V. A. les ha hecho merced. Y hecho la traza y el modelo del dicho baluarte [...], pareció que podría costar [...], siete mil y ocho cientos escudos o hasta ocho mil. Y los consejeros y personas que trataban de ello, dijeron con muy buena voluntad que querían gastar los siete mil escudos y que se acortase y estrechase un poco el dicho baluarte en cantidad hasta mil escudos de oro [...]. El ingeniero dijo que por ninguna manera convenía quitarle un palmo de la traza del dicho baluarte porque no haría los efectos necesarios para la defensa de la atarazana y ofensa de los enemigos. De todo di razón a don Bernardino de Mendoza [capitán de las galeras de Espańa] y me dijo que fuese al Consejo con el dicho ingeniero y que dijese a los consejeros que el baluarte se hiciese justa forma de la traza sin quitarle nada y que lo más costase de los siete mil escudos que V. A. lo mandaría pagar. ${ }^{33}$

Este tira y afloja entre la Corona y las autoridades territoriales por la financiación y consecuente comienzo o continuación de las diferentes obras y reformas que se hicieron a lo largo del siglo fue continuo, y fueron recogidos varios de estos episodios en el Dietari de la Diputació del General:

Sa magestat manava assentar y fer moltes galeres en la Dressana que té lo General en la present ciutat, y que de part de sa magestat pregava, a dits senyors deputats, continuasen la obra que allí tenen començada, segons que és necessari per la bona fabrica de dites galeres. ${ }^{34}$

Mossèn Hierònym Heredia, per part del excelllent loctinent general, vingué en lo consistori dels senyors deputats y digué a ses senyories que algunes arcades de la obra nova de la Dressana estaven perilloses de caure, per no ésser acabades de cloure, y que sa excelllència pregava a ses senyo-

33. AGS, GyM, leg. 47, f. I24, Carta de Juan Muñoz de Salazar al príncipe Felipe, Barcelona, 5 de agosto de 1552 .

34. Dietari de la Generalitat de Catalunya, vol. 2, I539-I578, p. 4I8, Barcelona, I4 de julio de 1573 . 
ries les manassen acabar de cloure o derrocar, perquè no estiguessen ab tant gran perill com estan de matar la gent. E dits senyors deputats li respongueren que veurien lo que se haurie de fer. ${ }^{35}$

E aprés sa excelllència digué, en effecte [...], de part de sa magestat, que acabassen si alguna obra faltava perquè se pogués exequutar lo fi per lo qual dits càrcers eren fets, y que axí mateix fessen continuar y acabar la obra de la Dressana que havia cessat sens justa causa, perquè altrament sa magestat ne restaria molt deservit. ${ }^{36}$

En cuanto a la maestranza, esta estaba compuesta, lógicamente, por artesanos y aprendices relacionados con la construcción y reparación de los barcos. Los llamados en catalán mestres d'aixa - y que en la documentación en castellano son llamados «maestres de aja», también conocidos como «maestres de hachuela» o "carpinteros de ribera»eran los principales artesanos implicados en la construcción de las galeras y constituían el grupo más numeroso de todos los artesanos, pues eran aquellos que se dedicaban a la labra de las piezas de madera que se necesitaban para la construcción de la embarcación. ${ }^{37}$ Dentro de la maestranza, existía el cargo de maestre de hacer galeras, que era otorgado a unos pocos de los muchos maestres y los convertía en capataces para el resto. Por encima de todos ellos se hallaba un único maestro mayor, encargado de supervisar todos los aspectos relativos a la construcción de los buques, así como de la elección de la madera y los materiales disponibles, y de dirigir y organizar el trabajo tanto de los diferentes carpinteros como del resto de los artesanos.

Gracias a la mucho más abundante documentación que existe a partir de la década de I570, hemos podido establecer la relación nominal de los diferentes maestros mayores que sirvieron en la fábrica de galeras de Barcelona desde 1567 , momento en que es nombrado para el

35. Ibidem, p. 528, Barcelona, 28 de mayo de 1577.

36. Ibidem, p. 533, Barcelona, 6 de agosto de 1577.

37. Lourdes Odriozola Oyarbide, «La construcción naval en Guipuzkoa. Siglos XVI-XviII", Itsas Memoria. Revista de Estudios Navales del País Vasco, 2 (1998), pp. I33-I34. 
cargo el genovés Bautista Jordán, con 25 ducados de sueldo al mes y con la autoridad necesaria para que "os dejen usar y ejercer el dicho oficio en las cosas y casos que lo podéis y debéis hacer, sin los poner ni consentir que sea puesto estorbo ni impedimento alguno». ${ }^{8} \mathrm{~A}$ su fallecimiento, en I582, fue sucedido por su hijo Bartolomé Jordán, ${ }^{39}$ si bien fue despedido junto con el resto de los oficiales y la maestranza por el virrey Manrique de Lara en I588, a raíz de los informes que, sobre él y el estado de la fábrica y los males que esta venía arrastrando, elaboró el superintendente de las atarazanas, el capitán Antonio de Alzate:

Que cuando por orden de V. M. fui a gobernar el Principado de Cataluña, hallé los oficiales de la Real Hacienda de V. M. muy señores de ella [...], despidiendo todos los comisarios y maestranza que trabajaba en las atarazanas [...].

Otro si la casa adonde vivía maestre Bautista Jordán, maestro mayor que fue de las dichas atarazanas, está dentro de las tapias de ellas, adonde ha vivido hasta ahora maestre Bartolomé Jordán su hijo, que no hay en medio sino una tapia baja por donde tengo entendido se han hecho algunas cosas indebidas en menoscabo de la Real Hacienda de V. M., por lo que soy de parecer, por constarme cierto, que allí no haya vivienda sino que se incorpore en las dichas atarazanas con lo cual se quitarán las ocasiones que hasta aquí ha habido. ${ }^{40}$

A Bartolomé Jordán lo sucedió en el cargo uno de los maestres de hacer galeras, Pedro Catalán, el cual había llegado desde la Casa de Contratación de Sevilla en 1585 después de trabajar varios años haciendo galeras para el rey en Lisboa..$^{4 \mathrm{I}}$ La crisis que atravesaba la fábrica de ga-

38. AGS, GyM, lib. 27, f. 319, El rey al maestre Bautista Jordán, Madrid, I7 de diciembre de 1567 .

39. AGS, GyM, lib. 38, f. 96, El rey al maestre Bartolomé Jordán, Lisboa, I3 de diciembre de 1582 .

40. AGS, GyM, leg. 264, f. 229, Manrique de Lara al rey, San Lorenzo, II de septiembre de 1589 .

4I. AGS, GyM, lib. 42, f. 289, El rey al maestre Pedro Catalán, 26 de septiembre de 1588 . 
leras se agravó en la década de I590, y la desorganización era tal que a la muerte de Pedro Catalán, el 26 de marzo de 1594, el cargo de maestro mayor quedó vacante, y así permaneció hasta I599, cuando ya el nuevo rey Felipe III, estando en Barcelona, nombró al maestre Jerónimo Verde para el cargo:

Por cuanto conviene a mi servicio dar nueva orden en las cosas de las atarazanas de esta ciudad de Barcelona y entre otras quitar el abuso de haber en ellas [...] [y] por los inconvenientes que resultan de ello como el tiempo lo ha manifestado, he acordado que tan solamente haya un maestro mayor de quien dependa la fábrica de las galeras y otras suertes de navíos que en las dichas atarazanas se hiciesen, como lo había por lo pasado sin haberse proveído este oficio en propiedad después que murió maestre Pedro Catalán, último maestro mayor de ellas, y teniendo muy buena relación de maestre Jerónimo Verde y la práctica y experiencia que tiene del arte de fabricar galeras como se ha visto por las que ha hecho en Nápoles y Génova y particularmente en la labor del buco de la galera real que fabricó en las dichas atarazanas y se varó y echó a la mar por el mes de abril pasado de este ańo [...], le elijo y nombro por tal maestro mayor de las dichas atarazanas..$^{42}$

Otros artesanos imprescindibles eran los calafates, que se encargaban de cerrar las juntas de las maderas con estopa y brea para que no entrara el agua. El proceso era bastante rudimentario y se llevaba a cabo en dos fases. En la primera, las juntas de las tablas de los fondos, costados y cubiertas se llenaban de estopa a fuerza de mazo y demás instrumentos que se tenían a propósito para ello — azuelas, martillos, hachas y barrenas, entre otros- Tras ello, el calafate procedía a calentar la brea, para seguidamente proceder a poner una espesa capa en el casco, la cubierta y los masteleros de la embarcación. ${ }^{43} \mathrm{Su}$ número era bastante más reducido que el de los carpinteros y muchas veces este oficio estuvo asociado al del carpintero de ribera, pues no era extraño que

42. AGS, GyM, lib. 82, f. 325, El rey al maestre Jerónimo Verde, Barcelona, 4 de junio de 1599 .

43. Odriozola, «La construcción naval», p. I35. 
estos asumieran su rol en caso de necesidad, como bien explica Fadrique de Portugal, arzobispo de Zaragoza y virrey de Cataluña, ante la falta de calafates:

Ante de ayer llegaron aquí setenta u ochenta calafates de Vizcaya y Guipúzcoa y aunque se han tardado, vienen a buen tiempo y en pocos días que trabajen no ternemos necesidad de ellos, porque acá tenemos otros setenta de la Terra y porque acostumbran los calafates a clavar las galeras, quitámosles este trabajo y habemos hecho barrenar y clavar a los maestros de hacha, que hay muchos, y con esto nos íbamos remediando lo mejor que podíamos, más con esta gente que es venida, vizcaína y guipuzcoana, somos fuera de la necesidad de los calafates. ${ }^{44}$

Cuando había mucho trabajo y el número de calafates era muy elevado, solía nombrarse a uno de estos como capataz, con el cargo de maestro mayor o cabo maestro de los calafates, para que, bajo la supervisión del maestro mayor, dirigiese el trabajo de sus compañeros. Como explica Pedro de Isunza, ese oficio "no consiste [...] sino en el nombre», pues tradicionalmente "se nombra el más antiguo y de mejor plática». ${ }^{45}$ Esta distinción, junto con otros nuevos cargos otorgados por Manrique de Lara en su reforma de la maestranza, causó agitación y malestar, pues eran dados como títulos, con sus privilegios y sueldo ordinario:

Por un título que ha dado [...] a Jerónimo Urpín [...], por el cual se le nombra por cabo maestro de los entalladores o fusteros de la fábrica de las galeras [...], [así como] por la cual hace merced a Francisco Griego, cabo maestro de los calafates [...]. No es justo que gane sueldo ordinario como el maestro mayor de la fábrica de las galeras y sus compańeros, sino tan solamente los días que trabajase el dicho cabo maestro de los fusteros, ansí como tampoco lo gane el cabo maestro de los calafates [...]. Nunca hubo cabo maestro de fusteros con título, ni tuvo sueldo ordinario [...], y lo poco que importa este oficio, pues el que verdaderamente lo adminis-

44. AGS, EST-K, leg. I69I, f. 49, El Arzobispo de Zaragoza al rey, Barcelona, 5 de marzo de 1537.

45. AGS, GyM, leg. 264, f. 247, Pedro de Isunza al rey, Barcelona, 9 de marzo de 1589. 
tra es el maestro mayor de la fábrica de las galeras, y ansí es fuerza que de aquí adelante haya controversia entre estos maestros, pues el cabo de los fusteros podrá decir que el maestro mayor no tiene que meterse en su oficio, de que a de resultar confusión y mala administración [...]. [Esto] me ha parecido advertir a V. M. por las obligaciones que tengo al oficio de comisario general de dicha fábrica. ${ }^{46}$

La coexistencia de varios cabos maestros o maestros mayores agravó el caos que ya reinaba en las atarazanas, y no se resolvería hasta pasada una década, cuando en el nombramiento de Jerónimo Verde el nuevo monarca especificó: "he acordado que tan solamente haya un maestro mayor de quien dependa la fábrica de las galeras».47

Entre los oficios relacionados con la construcción de galeras se encontraban también los mencionados fusteros o aserradores, que se encargaban de cortar y trabajar la madera, tanto en la fábrica como en los bosques.

Otro importante oficio era el de remolar; como indica el nombre, los remolares eran aquellos artesanos encargados de la fabricación de los remos empleados por las galeras. La demanda de remos fue constante, dado que, ya fuese por su uso al navegar, por chocar entre ellos, por enredarse con los de otra galera a causa de una tormenta o al formar la escuadra o, sobre todo, al entrar en batalla, los remos se partían y siempre había necesidad de ellos. Los remos eran incluidos entre los muchos recambios que las galeras contenían y entre las provisiones que estas adquirían al llegar a un arsenal aliado o cuando la escuadra iba a invernar.

Los cordaleros eran los operarios encargados de fabricar las cuerdas que se empleaban a bordo de los buques; estos cabos, según su grosor, constaban de dos, tres o cuatro cordones, que solían ser de cáñamo. ${ }^{48}$

46. Idem, leg. 264, f. 246, Pedro de Isunza al rey, Barcelona, 7 de mayo de 1589.

47. AGS, GyM, Lib. 82, ff. 325-326. Nombramiento de maestro mayor de las atarazanas de Barcelona en Jerónimo Verde. Barcelona, 24 de junio de 1599.

48. Odriozola, «La construcción naval», p. I35. 
Otra profesión destacada, aunque apenas mencionada en la documentación, es la de ancorero, el artesano que hacía las áncoras de los buques.

Asimismo, y aunque no formasen parte de la maestranza, se debe mencionar a otros profesionales vinculados al trabajo desarrollado en la fábrica, como son los bosqueroles, los transportistas, los herreros y los tejedores. Se encargaban, respectivamente, de cortar la madera en los bosques; transportarla tanto por tierra como por río y por mar; fabricar la clavazón — también llamada «clavos» 0 "puntillas»— y demás piezas metálicas; y tejer las velas o cotoninas empleadas en las galeras.

En la fábrica, además, colaboraban los hijos, criados y aprendices de los diferentes maestres y artesanos. Esto fue un motivo de disputa a causa del gran número que algunos de los artesanos tenían, pues se daba la circunstancia de que, aunque tenían asignado un sueldo, muchas veces solo existían en las nóminas. Es por ello que hubo de limitarse el número de éstos y restringirse los pagos, siendo simplemente privilegio de algunos de los maestros el poder sobre pasar dicho número: «no [se] pueda señalar [...] ningún salario a los aprendices ni hijos de maestros sino fuere con intervención y en presencia de los oficiales de la hacienda». Al mismo tiempo que se proponía exceptuar de esta limitación a los maestres catalanes:

Conviene mucho al servicio de S. M. mande que de aquí adelante no se admita ni pasen criados ningunos a los dichos maestros, sino tan solamente a los que en la costa de Cataluña fabrican navíos, saetías y barcos. Por razón que éstos tales los tienen en su casa a su pan y vino y los toman por asiento y salen de su poder maestros; lo que al contrario hacen los demás, que no los toman sino tanto cuanto hay fábrica por gangrenar la mitad del sueldo que ganan, cuanto más que algunos de ellos, no siendo aún maestros, pretenden llevarlos, que no siéndolo ellos no pueden ensenar a otros. ${ }^{49}$

49. AGS, GyM, leg. 264, f. 249, Bartolomé Jordán al rey, Barcelona, I589. 
Otra fuerza de trabajo considerable en la fábrica y aderezo de los buques eran los esclavos y forzados de las galeras - la llamada "chusma»—, ${ }^{\circ}$ máxime entre noviembre y marzo, los meses en que estas embarcaciones solían invernar en los diferentes puertos y arsenales: «se desembarquen de las galeras la mayor parte de los soldados, gente de cabo y esclavos, y duermen en las dichas atarazanas como lo hicieron el año pasado en veintidós días que allí estuvieron varando las galeras nuevas». ${ }^{5 \mathrm{I}}$

Sobre la invernada de las galeras no se han hecho demasiados estudios que traten el tema con la profundidad que merece, pero sabemos por la documentación que Barcelona y algunos enclaves de la costa catalana — Rosas, Palamós y Tortosa - eran puntos habituales donde las galeras se cobijaban durante los meses no adecuados para la navegación, por ser lugares que contaban con lo necesario para reparar y proveer la flota. "Venimos de Córcega a Génova el príncipe Doria mandó que estas galeras viniesen a invernar en Cataluña o donde S. M. mandase». ${ }^{52}$ A pesar de ello, Barcelona no era ni el predilecto ni el mejor de los lugares donde invernar, tal y como nos lo indican diferentes testimonios. Así escribía el veedor de las galeras sobre ello:

En Cataluña no hay puerto más tierra donde las galeras puedan invernar sin mucho riesgo de ellas y daño [...], no hay pan hecho [...] que la gente ha menester y es tierra fría para la chusma que ha de estar siempre en galera y no pueden en ningún puerto de Cataluña echar la palazón fuera porque a cada dicha borrasca de viento han de tener los remos en la mano y el invernar de las galeras ha de ser donde haya pan y tierra calienta para que la chusma esté buena y donde saque la palazón y se aderecen en la invernada todas las cosas necesarias de galera, desde el árbol a lo bajo, para que cuando venga el tiempo de navegar, esté todo a punto como convenga. ${ }^{53}$

50. Manuel Gracia Rivas, «Forzados en las galeras de España», en E. García Hernán y D. Maffi, eds., Estudios sobre guerra y sociedad en la Monarquia Hispánica: guerra maritima, estrategia, organización y cultura militar (I500-I700), Albatros Ediciones, Valencia, 2017, pp. 45-60.

5I. AGS, GyM, leg. 264, f. 236, Antonio de Alzate al rey [Barcelona, I589].

52. Idem, leg. II, f. I70, Pedro de Ońa al rey, Palamós, I4 de noviembre de I537.

53. Idem, leg. II, f. 95, Pedro de Ońa al rey, Génova, 6 de octubre de 1537. 


\section{Otro dice así:}

Estas naves están aquí a mucha perdición por ser la playa brava [...] [y] no estarían muy seguras de enemigos. Si son menester podríanse ir a Rosas donde estarían con más seguridad por ser puerto y también gastarán menos de la jarcia y de lo demás. ${ }^{44}$

Tanto para los buques como para la gente de las galeras, se prefería el sur peninsular — donde destacaban Cartagena, Málaga, El Puerto de Santa María y Gibraltar por ser lugares con un invierno más benigno- - dado que sus costas, a pesar de carecer de una infraestructura como las Atarazanas Reales, sí contaban con unos magníficos puertos y, en general, eran zonas más prósperas y abundantes, donde resultaba fácil y barato reabastecerse de vituallas y otros materiales. Esta predilección de los capitanes y patrones de las galeras por ir al sur a invernar fue más habitual cuando la flota real estaba administrada por asiento con particulares, pues en muchos de estos contratos se establecía que era responsabilidad del asentista asumir el coste de las provisiones.

En cuanto a los oficiales de la atarazana, destacan el comisario general, encargado de la fábrica y de todas las cosas a ella anexas; el veedor y el contador, que llevaban la cuenta y razón, tanto general como particular, de todo lo que se despachaba - en muchas ocasiones, no respondían a cargos específicos para la fábrica de galeras, sino que abarcaban todo el Principado y los condados-; el mayordomo de las atarazanas, tradicionalmente llamado drassaner, que tenía el control de todos los materiales, bastimentos, municiones y pertrechos de la fábrica, y que estaba ayudado por un sobrestante mayor; y el portalero, que custodiaba las llaves de las atarazanas y que entre otras cosas «da cuenta de lo que entra y sale de noche y no haya robos».55 Además había numerosos entretenidos, criados y otros oficiales reales que el rey podía enviar de forma ocasional.

54. Idem, leg. 47, f. 202, Juan Muñoz de Salazar al rey, Barcelona, I3 de septiembre de 1552 .

55. Idem, leg. 264, f. 240, Pedro de Isunza al rey, Barcelona, 7 de mayo de 1589. 
Todos ellos estaban bajo la supervisión del superintendente de las atarazanas, el cual en ocasiones ocupaba también el cargo de mayordomo. Por encima de estos oficiales se encontraba el virrey de Cataluña, aunque no por ostentar ese título, sino más bien por las competencias que tenía como capitán general del Principado. No fue hasta la llegada de García de Toledo cuando la implicación directa del virrey en los asuntos de las atarazanas y de galeras pasó a ser una de las funciones principales del cargo. Nombrado en I558, con una dilatada carrera militar y como capitán de galeras, fue el primer virrey designado para Cataluña por parte de Felipe II cuando este asumió el trono, y fue uno de los artífices de la regeneración de la marina de la Monarquía en el Mediterráneo. En 1564 le concedieron el título de capitán general del mar Mediterráneo y Adriático y pasó también a ocupar el cargo de virrey de Sicilia. ${ }^{56}$ Los sucesivos virreyes de Cataluña tuvieron que asumir como una de sus tareas principales la gestión de la fábrica de las galeras. En este cometido solía ayudar al virrey el gobernador de Cataluña, cargo que durante todo el siglo XVI estuvo en manos de una rama menor de la familia Cardona. ${ }^{57}$ A su vez, los capitanes de las escuadras de galeras tenían también autoridad dentro de los quehaceres de la fábrica, aunque este hecho era más debido a su experiencia en asuntos de la mar, y

56. Sobre García de Toledo y su etapa como virrey puede verse mi trabajo «El inicio de la recuperación naval hispana en el Mediterráneo y la construcción de galeras en Barcelona durante el virreinato de García de Toledo (I558-1564)", en M. á. Pérez Samper y J. L. Betrán Moya, eds., Nuevas perspectivas de investigación en Historia Moderna: Economía, sociedad, política y cultura en el mundo hispánico. IV Encuentro de Jóvenes Investigadores en Historia Moderna, Fundación Española de Historia Moderna, Madrid, 20I8, pp. 529-54I.

57. Pedro de Cardona y Enríquez, barón de Azuébar, era uno de los hijos del primer duque de Cardona, Joan Ramon Folc de Cardona (I446-I513), y obtuvo el cargo de gobernador de Cataluña en I509 - hasta el momento vinculado a la familia Requesens-, por su matrimonio con Joana de Requesens. A su muerte, en I546, hereda el título su hijo Pedro de Cardona y Requesens, el cual tendrá un papel muy activo en la fábrica hasta que falleció, en I593, momento en que su hijo Enrique lo heredaría. Pedro de Cardona y Requesens era, a su vez, primo de Juan de Cardona, capitán de galeras al servicio de García de Toledo en Sicilia. 
porque en última instancia eran ellos quienes iban a emplearlas, que no al cargo que ostentaban. Quien sí tenía el deber de inspeccionar e incluso aplicar justicia era el capitán general..$^{58}$

Esta multitud de cargos, oficiales y ministros no solo del rey, sino también de la ciudad y del Principado, con funciones superpuestas o con los límites poco definidos, hacía que en ocasiones, y de la misma manera que hemos visto que sucedía en el caso de los maestros mayores, surgiesen conflictos. Especialmente problemáticos eran los que implicaban a los oficiales del rey contra los de territorio. Así escribía el prior don Hernando de Toledo — virrey entre I57I y I580-, en I574, a raíz del conflicto que se originó cuando el comendador Gil de Andrade, capitán de galeras del rey, llegó a Palamós para abastecerse de provisiones y dinero, cuando estaba vigente la prohibición de sacar — sin licencia del rey- dinero de esos reinos:

Los sacaban lícitamente y que por privilegio de esta ciudad e ir despachado del [capitán] general y otras pretensiones lo podían hacer. Se ha alterado esta tierra pareciéndoles les toman su dinero sin conocimiento de causa, lo cual y sacarlos de Cataluña es contra fuero y constituciones del reino. Visto esto y que ninguna otra cosa los aquietará que saber que el dinero está en Génova a mi requisión [...], hecho lo cual los oiré yo de justicia. No obstante que pretendo que V. M. la tiene y se condenará o librará el dinero conforme a ella. ${ }^{59}$

Visto todo esto, podemos hacernos una idea de la importancia que las Atarazanas Reales de Barcelona tenían para la Corona, tanto en el ámbito político, como en el económico y, sobre todo, en el militar. Es por ello que el edificio contaba de manera ordinaria con un grupo de cincuenta soldados, además de su sargento y su capitán, que se encargaban de custodiar el edificio y su contenido tanto interna como exter-

58. Miguel Ángel de Bunes Ibarra, «El oficio de Capitán General del Mar Mediterráneo a lo largo del siglo XVI», en García Hernán y Maffi, Estudios sobre guerra..., pp. 6I-78.

59. AGS, GyM, leg. 78, f. 28, El prior don Hernando al rey, Barcelona, 2I de julio de I574. 
namente. Sin embargo, estos guardas que en teoría debían velar por la seguridad y los intereses del rey, fueron un foco de problemas, y estos se hicieron más evidentes a finales del siglo, cuando la actividad en el edificio decayó de forma muy notable. Se les acusaba de no ser de utilidad y de robar: "los cuales no son de ningún servicio, sino de llevar sueldo y quemar mucha madera de que es buena para la fábrica y hurtar las herramientas y clavazón y otras muchas cosas». ${ }^{60}$ También, de conducta disoluta, de permitir la entrada y salida de extrańos y de tener organizado un casino:

El juego de las dichas atarazanas [...] [está] causando esto tan mala guarda en ellas por estar todos los soldados ocupados en jugar, ver jugar o tener a su cargo el juego que, en la fábrica de las dichas quince galeras, está probado en el descargo [...] haberse hurtado más de mil ducados de fusta, clavazón y otras cosas. ${ }^{61}$

El principal promotor y protector de todo ello no era otro que Matías Cárcamo, el mismo capitán de los soldados, que a su vez era secretario del virrey Manrique de Lara, y que despidió e inculpó de los hechos tanto al portalero como al sargento de la guarda, por no querer estos participar. Así lo relata Pedro de Isunza:

Cárcamo enviaba a los soldados de las atarazanas fuera de ciudad a sus negocios, hasta darles licencia para acompañar una mujer perdida hasta Perpiñán. Y que servía de dichos soldados y los ponía en guarda de su persona. Que sin orden de don Manrique tuvo preso más de veinte días al sargento de las atarazanas, que hoy sirve en la cárcel real de esta ciudad de Barcelona, por solo quitarle la amistad de una mujer de la cual el Cárcamo se aprovechó después. Y que también prendió dos otras veces al portalero de las atarazanas sin estar subordinado al dicho Cárcamo y todo lo dicho y otras muchas cosas que se probarán mandándolo V. M. ${ }^{62}$

6o. Idem, leg. 264, f. 249, Bartolomé Jordán al rey, Barcelona, I589.

6I. Idem, leg. 252, f. 2II, Pedro de Isunza al rey, Hostalric, I2 de octubre de I589.

62. Idem, leg. 264, f. 242, Pedro de Isunza al rey, Barcelona, 7 de mayo de 1589. 


\section{En otra añadía:}

El capitán en aquella casa no sirve de nada sino de lo dicho, de poner confusión en ella y de tirar su sueldo [...]. Torno a decir por la misma razón que el juego ha de mandar V. M. en todo caso extirparse de aquella casa, porque además de los inconvenientes dichos, por no estar sujeta a la justicia de la tierra, van allá tantos géneros de gentes, no a solo jugar su dinero, pero plata, vestidos y joyas de sus mujeres, y aun hurtadas, que al cabo del año se destruyen mil casas. ${ }^{63}$

El capitán Antonio de Alzate, nacido en Nápoles, aunque perteneciente a un linaje navarro, contaba con una gran experiencia en lo tocante a las galeras y con un excelente y largo historial al servicio del rey cuando fue nombrado superintendente de las Atarazanas Reales de Barcelona en 1587 . Entre sus méritos destacaban haber llevado hasta Sevilla para su decoración la galera real hecha en Barcelona en I 568 para don Juan de Austria; haber servido en las galeras de España y Nápoles durante once ańos; capitanear una nave en Lepanto, destacándose en la jornada de Portugal, donde después se le encargó en Lisboa capitanear la guardia de cien arcabuceros que protegía la casa real y alhóndiga. Además, se ocupó de la descarga de los cargamentos de especias que venían de la India oriental; y más tarde, de regreso a Nápoles, fue designado por el duque de Osuna para que tasara las veintiséis galeras que se asignaron por asiento. ${ }^{64}$ También tenía conocimiento de construcción y armamento de las galeras y conocía bien otras atarazanas, así como sabía desenvolverse en tareas contables y administrativas. Con este expediente no es de extrañar que el rey le encomendara auditar la deficiente fábrica de Barcelona para que elaborase un memorial de propuestas dirigidas a reformar la institución y maestranza. Es por ello que sobre los soldados que custodian las atarazanas propone:

Para la guardia y custodia de las dichas atarazanas hay de ordinario cincuenta soldados con su capitán, sargento y dos cabos a tambor y pífano

63. Idem, leg. 252, f. 2II, Pedro de Isunza al rey, Hostalric, I2 de octubre de 1589.

64. Idem, leg. 264, f. 228, Memorial del Capitán Antonio de Alzate [s. f.]. 
los cuales hacen costa de 2232 ducados. Parece que S. M. podría ahorrar todo esto con ordenar que de Perpinán viniesen de cuatro en cuatro meses dos escuadras de soldados [cada escuadra contaba con 25 hombres] de las compañías que allí residen con su sargento que los gobierne, pues demás de que estos servirían con más disciplina y cuidado de lo que lo hacen los que en las dichas atarazanas ha habido por lo pasado. Se excusarían los excesos y desórdenes que hay de hurtos a juegos y otros vicios de gente ruin que se acoge en las dichas atarazanas. ${ }^{65}$

En otro orden de cosas, habiendo hablado sobre algunas de las problemáticas y características de la fábrica de galeras y los diferentes oficios que participaban en esta empresa, consideramos necesario hablar ahora sobre el número de ellos. Resulta difícil de precisar la cantidad de trabajadores, pues fluctuó mucho dependiendo del período y de la necesidad de fabricar nuevas embarcaciones. Según nuestras indagaciones, una vez que Felipe II decide priorizar la lucha en el Mediteráneo a partir de su regreso a Espańa en 1559, contando solo la maestranza que operaba en las atarazanas, sus anejos y la playa, pudieron superarse perfectamente los quinientos trabajadores, aunque podríamos considerar que la media de esos años de tanta actividad fabril rondaba la mitad de ese número, y que serían unos cien en las etapas de menor actividad. Para abastecer la necesidad de mano de obra de las atarazanas se hubo de recurrir al exterior, pues los carpinteros de ribera y calafates de la costa catalana eran insuficientes, e incluso sus obras no eran demasiado apreciadas por los capitanes, como nos describe García de Toledo:

Eraso me ha enviado traslado de un capítulo que el gobernador de Cataluña [Pedro de Cardona] ha escrito acerca de las galeras que en Barcelona se hacen, y si el gobernador tuviese experiencia de aquello como tiene la voluntad al servicio de V. M., hablaría de otra manera de en ello. Las galeras que en Cataluña se han hecho por mano de maestros catalanes son pesadísimas, y así ha sido menester hacerlas tomar por fuerza a los

65. Idem, leg. 264, f. 23I, Antonio de Alzate al rey [Barcelona, I588]. 
capitanes, porque siendo de la manera que digo revienta las chusmas para hacerlas andar y siempre es necesario llevarlas arrastrando, tanto más si se arman de chusma nueva; y aunque las que hacen maestros genoveses costasen mil ducados más cada una por las causas que digo se gana harto más en ellas que no en las que hacen los catalanes, pues las unas sirven y son las que conviene, y con las otras se tiene el trabajo y daño que he dicho.

En lo que dice de la madera está claro que habiéndose cortado ahora tres ańos [durante su gobierno] tanta cantidad de ella, ha de haber en las atarazanas madera de corazón sobrada de la fábrica pasada; pero él [Cardona] es tan apasionado por sus maestros catalanes que le parece que es muy gran verdad todo lo que ellos le dicen, y pues a mí se me entiende algo de esto, bien puede V. M. creer que no me engaño en ello, y que [papel dańado; ilegible] al servicio de V. M. que no se hubieran enviado a los maestros de Génova, y ha sido harto inconveniente y daño no haberlas hecho hacer por sus manos. ${ }^{66}$

Debido a la necesidad de trabajadores, así como a lo prestigiados que eran los de algunas otras tradiciones constructivas, el trasvase de efectivos y la recluta mediante persuasión y paga justa fue un episodio continuo. Se reclutaban maestros de aja, calafates y remolares de Valencia, el Reino de Mallorca, de las Cuatro Villas y el resto del Cantábrico, Nápoles, Génova..., pero era en las provincias vascas —Vizcaya, Guipúzcoa - y Liguria donde se hacían más contrataciones: «dificultad hay en la maestranza por ser poca la de Cataluña para tanta máquina y [...] podría hacer [...] venir trescientos maestros de la ribera de Génova [...] y [también] será necesidad hacerlos venir de Vizcaya». ${ }^{67}$ Los maestres genoveses eran los más reputados, si bien contaban también con testimonios como el siguiente:

Los maestros genoveses, la mayor parte de ellos han caído malos y trabajan muy poco y si hubiera hallado algún pasaje razonable hubiera enviado

66. Colección de Documentos Históricos Inéditos para la Historia de España, vol. 39, pp. 325-335, García de Toledo al rey, Mesina, 25 de marzo de 1565.

67. AGS, GyM, leg. 249, f. 240, Antonio de Alzate al rey [I589]. 
la mayor parte o todos. Porque trabajan muy poco y son muy costosos, un tercio más que los catalanes. ${ }^{68}$

A pesar de este tipo de precedentes, el rey confiaba mucho en el criterio de García de Toledo, por lo que su opinión prevaleció y en 1567 se contrató como maestro mayor al genovés Bautista Jordán.

También hay que señalar que los trabajadores más valorados y, por ello, más costosos, fueron los vascos. Casado Soto dice, por ejemplo, que Felipe II, después de los desastres de Gelves y La Herradura, en I562, mandó que se trasladaran a Barcelona doscientos carpinteros de ribera y cien calafates de la zona del Cantábrico. ${ }^{69}$ Estos trescientos trabajadores, sin embargo, no llegaron a Barcelona debido a que los carpinteros vizcaínos pedían 3 reales y medio de jornal, mientras que los catalanes cobraban I real y medio y García de Toledo estaba dispuesto a pagar solo 2 reales. ${ }^{70}$ Esta situación se dio en más ocasiones:

Y por haber escrito el prior don Hernando que con haber llegado de Valencia treinta y un oficiales entre maestros y mozos para las galeras y con otros veinticuatro que había antes avisado tenía que son cincuenta y cinco. Pues los de Vizcaya salían con dificultad de sus casas. Podría V. M. que se queden porque también llegarán tarde y con los que tiene se acabará aquella obra sin que vengan tampoco de Génova. ${ }^{71}$

Asimismo, y aunque las grandes contrataciones fueran procedentes de ciertas regiones, encontramos maestres y trabajadores de diferentes naciones y por tanto poseedores de otras técnicas y tradiciones constructivas. Había gente de Ragusa, Grecia, Sicilia, Sevilla, Provenza, Portugal y Venecia. El arsenal catalán concentró la mayor parte de la actividad fa-

68. Idem, leg. 47, f. 78, Juan Muñoz de Salazar al rey, Barcelona, 20 de julio de I552.

69. José Luis CASAdo Soto, «El Cantábrico y las galeras hispanas de la Edad Media a la Moderna", Itsas Memoria. Revista de Estudios Marítimos del País Vasco, 4 (2003), p. 550.

70. Cesáreo Fernández Duro, A la mar, madera. Libro quinto de las disquisiciones náuticas, Madrid, I880, p. 269.

7I. AGS, GyM, leg. 78, f. 234, Minuta al rey. 
bril de esta gran empresa de casi un siglo de duración y por ello es natural que entre sus muros trabajasen gentes venidas de todo el Mediterráneo, dado que, como hemos visto, a veces eran más apreciados que los locales. Esta consideración a la baja de los artesanos catalanes a su vez se reflejaba en los salarios escasos, y acabó trayendo el descontento a la fábrica, máxime cuando la situación se agravaba por el progresivo encarecimiento del coste de la guerra en el Mediterráneo y las dificultades económicas de la Corona. Esto era lo que la propia maestranza explicaba en carta al rey:

Los maestros de aja y calafates y otros oficiales de hacer galeras que trabajan en la tarazana de Barcelona en servicio de V. M. dicen que [...] presentaban [...] al poco sueldo que cada uno de ellos tiene, como es a cada maestro de aja dos reales y medio cada día y a los calafates y serradores dos reales cada día, de los cuales se han de sustentar ellos y sus casas y familias, siendo como son la mayor parte de los dichos maestros y oficiales de fuera de Barcelona, algunos de más de veinte leguas. No pueden sustentarse antes con el celo que tienen y han tenido de servir a V. M. han asistido en el ejercicio de sus oficios y han gastado y consumido la mayor parte y casi todas sus haciendas, mediante lo cual, teniendo consideración a que por ser tan poco el dicho sueldo, muchos de los dichos maestros, muchas veces dejaban los dichos cargos y se huían y hacíanse marineros y los tomaban y cautivaban los infieles, los cuales cautivados, los hacen trabajar de sus oficios y por ningún dinero los dan en rescate. Y según esto, podrá venir tiempo que no se halle cuando sea menester un maestro en aquel Principado por ninguna casa y se advierte a V. M. que cuando se ofrece querer hacer galeras, de los que hay que se esconden y huyen por no trabajar con tan poco salario [...]. Suplican a V. M. fuese servido de mandarles crecer a cada maestro de aja a cuatro reales cada día y a los calafates y serradores a tres reales y medio cada día, lo cual será cómodo sueldo para la sustentación de ellos y sus familias, y a los que vienen de fuera de Barcelona, les mande V. M. dar por el gasto del camino, alguna cosa de más del dicho sueldo y con ello continuarán todas sus vidas el servir a V. M. en la dicha tarazana como desean y tienen voluntad..$^{72}$

72. Idem, leg. 24I, f. 73, La maestranza de hacer galeras de las Atarazanas de Barcelona al rey, Barcelona, 26 de septiembre de 1588 . 


\section{Las Atarazanas: mucho más que galeras}

Llegados a este punto, podemos afirmar que hay disponible información necesaria para intentar dar respuesta a las muchas dudas e incógnitas que tanto las Atarazanas Reales de Barcelona como la construcción de los buques nos plantean. $Y$ es que las galeras requerían de un aparato logístico enorme y muy costoso, cuya gestión y administración ha dejado una abundante documentación en los archivos — de todos ellos, sin lugar a dudas, el principal es el Archivo General de Simancas-. Encontramos desde la provisión de los materiales para su construcción y mantenimiento, las discusiones de tamaños, formas y estructuras, la alimentación de las tripulaciones, la dirección y organización de las escuadras y flotas, sus contabilidades y rendimientos de cuentas, hasta memoriales e incluso verdaderos tratados de construcción, entre mucha otra información. Gracias a ello hemos podido llenar el vacío informativo que hallamos al inicio de este trabajo de estudio. ${ }^{73}$

Asimismo, esta investigación nos permite abordar otros temas que, sin ser parte del sujeto de forma explícita, sí que estuvieron intrínsecamente vinculados a él, como por ejemplo el comercio. Y es que la documentación no deja de repetirnos que Cataluña por sí sola no podía abastecer la demanda de mano de obra, y tampoco la de los materiales y los bienes necesarios que la lucha en el Mediterráneo requería. Por tanto se produjo un continuo flujo de dinero, mercancías y materiales, no solo entre los demás territorios del rey —Flandes, Nápoles, Sicilia, Navarra, Valencia, Andalucía...- y sus aliados —Génova, Saboya, Portugal...-, sino también con enemigos y rivales - Francia, Venecia, Inglaterra...- - y regiones más remotas con las que apenas existía relación diplomática — Suecia, Dinamarca, Prusia, Polonia...

De entre todos esos materiales, el principal y más interesante de rastrear es la madera. A pesar de ser bien sabido, este ha sido un tema

73. A. Jorge Aguilera López, «Fabricando el socorro de Malta: Las Atarazanas Reales de Barcelona en la política mediterránea de Felipe II (I556-1565)», Trabajo de fin de máster, Facultat de Geografia i Història, Universitat de Barcelona, 20I5. 
poco estudiado, al menos para el caso catalán. Los bosques catalanes sufrieron muchísimo las consecuencias de esta política de construcción naval a gran escala. La situación llegó a ser preocupantes a mediados del reinado de Felipe II, y es por ello que la Corona intentó proteger los bosques y evitar, así, quedarse sin suministro de madera, por lo que promovió políticas de protección de bosques y montes y de plantación de árboles y legisló de diferente manera para este propósito, creando a su vez cargos como el de superintendente de bosques y plantíos - llamado en el Principado conservador de boscos - . La deforestación en esta época se ha venido investigando para zonas del Atlántico, ${ }^{74}$ en cambio, para el Principado no nos consta la existencia de estudios amplios relativos a esta cuestión. Aun así, la documentación que manejamos nos permite indagar en esta problemática, que si bien, como hemos dicho, a mediados del reinado de Felipe II era preocupante, a finales del mismo era crítica:

Habiéndose acabado los árboles del Montseny, que es un bosque en Cataluña a cuatro leguas de Blanes, de donde se proveían de ellos los años pasados las galeras [...], ordenó S. M. [...] se enviasen a buscar árboles por todos los bosques de Cataluña. ${ }^{75}$

Otro aspecto importante es el económico, no solo en lo relativo a la construcción, financiación y mantenimiento de las flotas, sino también con relación al impacto económico que esta gran actividad política, comercial, militar e industrial generó en la ciudad de Barcelona y, en general, en todo el Principado; y a su vez cómo afectó el progresivo

74. Álvaro Aragón Ruano, El bosque guipuzcoano en la Edad Moderna: aprovechamiento, ordenamiento legal y conflictividad, Aranzadi Zientzi Elkartea, Donostia San Sebastián, 20oI; David Goodman, El poderio naval español. Historia de la armada española del siglo XVII, Península, Barcelona, 200I; Koldo Trápaga Monchet, «El estudio de los bosques reales de Portugal a través de la legislación forestal en las dinastías Avis, Habsburgo y Braganza (c. I435-I650)", Philostrato. Revista de Historia y Arte, I (2017), pp. 5-27.

75. AGS, GyM, leg. 249, f. 24I, Antonio de Alzate al rey, Madrid, 22 de junio de 1589. 
descenso de la misma a partir de la década de i580. Pues así como Felipe II puso toda su atención y sus recursos a disposición de la lucha en el Mediterráneo, lo mismo hizo con Flandes una vez que la revuelta se empezó a complicar, de manera que todo ese interés y, sobre todo, los recursos se fueron hacia el frente atlántico. Cosa que el propio don Juan de Austria, capitán general del Mediterráneo, advirtió con preocupación. Así escribía a su hermano acerca de sus planes sobre Túnez y de proteger los presidios y dominar esa zona para aislar a los corsarios de Berbería del apoyo otomano:

Para más seguridad de aquellas plazas di orden que se metiese en ellas la infantería española que estaba en Cerdeña, no hubo lugar por haber V. M. enviado a mandar precisamente que se llevase a Flandes y a mí no me quedó otra gente de que poder disponer [...]. La resolución que agora parece muy acertada, puede ser después de años a, como [...] enviar la dicha gente a Flandes, se tomó por impedir con ella la seguridad de La Goleta y Túnez que tanto importan. ${ }^{76}$

Flandes empezó a interponerse en la política y seguridad del Mediterráneo. Como decimos, este fue el inicio del cambio. La Monarquía a partir de ese momento centró toda su atención en la revuelta holandesa, en Inglaterra y en las guerras de religión francesas. Se desplazó, por tanto, no solo en el eje vertical, de sur a norte, sino también en el horizontal, de este a oeste, es decir, que se pasó del Mediterráneo al Atlántico, y de construir galeras a construir galeones. Con ello, las provincias mediterráneas vieron afectadas muy seriamente sus economías e industrias, las cuales durante décadas se habían estado focalizando en una construcción naval especializada que ahora entraba en decadencia de forma abrupta. ${ }^{77}$ Se debe matizar, sin embargo, que no es que después de la década de 1580 la galera como tal entrara en crisis, sino que lo que entró en decadencia fue el sistema de grandes flotas de galeras; por tanto, fue la estrategia y no el instrumento lo que cambió, básica-

76. Idem, leg. 78 , f. 7 , Don Juan de Austria al rey, Palermo, Io de septiembre de I574.

77. Thомpson, «Las galeras en la política», pp. I2I y I22. 
mente porque las grandes flotas dejarían de ser necesarias por aquel entonces. Pues, aunque el Imperio otomano seguía existiendo, a raíz de las diferentes treguas secretas firmadas entre Felipe II y Murad III - y que acabaron siendo, de facto, una paz duradera a partir de $158 \mathrm{I}$-, el peligro otomano empezó a percibirse como algo lejano, ${ }^{78}$ restando como único problema con el Islam la que norteafricana, que no requería de grandes flotas para ser combatida.

78. María José Rodríguez-Salgado, Felipe II, el «Paladín de la cristiandad» y la paz con el turco, Universidad de Valladolid, Valladolid, 2004. 